\title{
To heal or not to heal: the ACL dilemma
}

\author{
Andrea Ferretti
}

Anterior cruciate ligament (ACL) reconstruction represents one of the most commonly performed surgical procedures worldwide, with very good results in terms of restoring knee stability, recovery of function, and return to sports at a preinjury level [1].

Although substantial differences still exist among surgeons regarding the type of reconstruction (autologous, homologous, or allografts) and graft choice in case of autologous grafting (hamstrings, patellar tendon, or quadriceps tendon), there is general agreement that, when surgery is needed, ACL reconstruction is the gold standard [2].

However, in the last few years, the number of papers on direct repair of ACL published in international literature has increased, witnessing growing interest in this topic [3-7]. It appears that ACL repair should be reconsidered as an alternative to reconstruction, taking advantage of new surgical materials, devices, and techniques.

In fact, ACL repair was the first procedure ever reported in the history of ACL surgery, although the results of this pioneering surgery were never trustworthily reported [8-11]. Since the beginning of modern ACL surgery, dating back to the 1960s, results of ACL repair, as reported by several authors over the years, were overall unsatisfactory, leading knee surgeons to the conclusion that a torn ACL was irreparable.

However, deep study of the biological basis regulating the different phases of healing of human ligaments reveals that even the ACL seems to have potential to heal [12]. The blood supply, whose anatomy was deeply investigated by an Italian researcher, is rich in vessels and anastomosis, providing adequate supply to all kinds and sites of tears (proximal, distal, and midsubstance) $[13,14]$. The early platelet clot seems to be able to deliver

\footnotetext{
*Correspondence: aferretti51@virgilio.it

Orthopaedic Unit and Kirk Kilgour Sports Injury Centre, S. Andrea Hospital, University of Rome La Sapienza, Rome, Italy
}

growth factors that attract mesenchymal cells, as well as governing their differentiation towards fibroblasts and myofibroblasts. In fact, these cells are found in large numbers in the stumps of a torn ACL, even months after an injury, as well as type 3 collagen, a precursor of the eventual ligamentous type 1 collagen [15].

Based on these factors, why is the ACL still somehow considered irreparable by so many surgeons? The answer could be anatomical and mechanical rather than biological. Lack of healing could be related to the intraarticular environment of this ligament, which could avoid formation of a suitable provisional bridge between the disrupted stumps [16]. Gravity would cause the distal stump to bend towards the posterior cruciate ligament (PCL), where it would eventually attach, taking advantage of the PCL's rich synovial blood supply. Attachment of the ACL to the PCL results in a viable but nonfunctional ligament [15].

Should this be the case, surgery could actually be able to help Nature complete this healing process by reestablishing the continuity and tension of the ligament and promoting scar tissue formation and differentiation.

Returning to recently published literature on ACL repair, we notice that reported results are highly conflicting, with acceptable outcomes ranging from $40 \%$ to up to $90 \%$. [17-20]. This great variability could be explained by the great variety of indications, surgical techniques, materials, and rehabilitation protocols.

This issue of JOT includes a paper written in collaboration with the Hospital for Special Surgery, presenting preliminary results of a technique for ACL repair evaluated by sequential magnetic resonance imaging (MRI). Inspection of some of the quite astonishing images shows that the presented technique, if used in select cases of acute ACL tears, could lead to encouraging results.

However, even if ACL repair may appear to be an attractive procedure to minimize morbidity and avoid harvesting-related complications, all preliminary 
outcomes should be taken very cautiously. Moreover, the correct indication in terms of timing of surgery (acute, subacute, and chronic), type of tears (proximal, distal, and midsubstance), age, sex, activity level, associated injuries, severity of instability, surgical technique, use of augmentation, etc. must be further addressed and possibly elucidated.

It seems easily predictable that, in the near future, other centers and surgeons will deal with this new challenging topic of ACL surgery and that the issue of "to repair or not repair" will become one of the hot topics at all future meetings and congresses; more submissions are expected from several authors to be considered for publication in all major specialized journals.

\section{Abbreviations}

ACL: Anterior cruciate ligament; MRI: Magnetic resonance imaging; PCL: Posterior cruciate ligament.

\section{Acknowledgements}

Not applicable.

\section{Authors' contributions}

A.F. conceived this study and prepared and edited the manuscript. The author read and approved the final manuscript.

\section{Funding}

The author received no financial support for the research, authorship, and/or publication of this article.

\section{Availability of data and materials}

Not applicable

Ethics approval and consent to participate

Not applicable.

\section{Consent for publication}

Not applicable.

\section{Competing interests}

A.F. is a consultant for Arthrex.

Received: 3 June 2020 Accepted: 27 July 2020

Published online: 29 August 2020

\section{References}

1. Mall NA, Chalmers PN, Moric M, Tanaka MJ, Cole BJ, Bach BR Jr, Paletta GA Jr (2014) Incidence and trends of anterior cruciate ligament reconstruction in the United States. Am J Sports Med 42:2363-2370

2. Gabler CM, Jacobs CA, Howard JS, Mattacola CG (2016) Comparison of graft failure rate between autografts placed via an anatomic anterior cruciate ligament reconstruction technique: a systematic review, metaanalysis, and meta-regression. Am J Sports Med 44:1069-1079
3. Difelice GS, Villegas C, Taylor S (2015) Anterior cruciate ligament preservation: early results of a novel arthroscopic technique for suture anchor primary anterior cruciate ligament repair. Arthroscopy 31:2162-2171

4. Van Der List JP, Mintz DN, DiFelice GS (2019) Postoperative magnetic resonance imaging following arthroscopic primary anterior cruciate ligament repair. Adv Orthop 2019:5940195

5. Achtnich A, Herbst E, Forkel P, Metzlaff S, Sprenker F, Imhoff AB, Petersen W (2016) Acute proximal anterior cruciate ligament tears: outcomes after arthroscopic suture anchor repair versus anatomic single-bundle reconstruction. Arthroscopy 32:2562-2569

6. De Smet E, Heusdens CHW, Parizel PM, Van Dyck P (2019) MRI following primary repair of the anterior cruciate ligament. Clin Radiol 74:649. e1-649.e10

7. Gobbi A, Whyte GP (2018) Long-term outcomes of primary repair of the anterior cruciate ligament combined with biologic healing augmentation to treat incomplete tears. Am J Sports Med 46:3368-3377

8. Robson AW (1903) VI. Ruptured crucial ligaments and their repair by operation. Ann Surg 37:716-718

9. Campbell WC (1939) Reconstruction of the ligaments of the knee. Am J Surg 43:473-480

10. O'Donoghue DH (1955) An analysis of end results of surgical treatment of major injuries to the ligaments of the knee. J Bone Joint Surg Am 37:1-13 (passim)

11. Marshall JL, Warren RF, Wickiewicz TL (1982) Primary surgical treatment of anterior cruciate ligament lesions. Am J Sports Med 10:103-107

12. Roe J, Salmon L, Waller A et al (2016) Spontaneous healing of the ruptured anterior cruciate ligament A case series of 21 patients. Orthop J Sports Med 4(7):2325967. https://doi.org/10.1177/2325967116s00080

13. Scapinelli $R$ (1997) Vascular anatomy of the human cruciate ligaments and surrounding structures. Clin Anat 10:151-162

14. Arnoczky SP (1985) Blood supply to the anterior cruciate ligament and supporting structures. Orthop Clin North Am 16:15-28

15. Nguyen DT, Ramwadhdoebe TH, van der Hart CP, Blankevoort L, Tak PP, van Dijk CN (2014) Intrinsic healing response of the human anterior cruciate ligament: an histological study of reattached ACL remnants. J Orthop Res 32:296-301

16. Murray MM, Martin SD, Martin TL, Spector M (2000) Histological changes in the human anterior cruciate ligament after rupture. J Bone Joint Surg Am 82:1387-1397

17. van der List JP, Vermeijden HD, Sierevelt IN, Di Felice GS, van Noort A, Kerkhoffs GMMJ (2019) Arthroscopic primary repair of proximal anterior cruciate ligament tears seems safe but higher level of evidence is needed: a systematic review and meta-analysis of recent literature. Knee Surgery Sports Traumatol Arthrosc. https://doi.org/10.1007/s00167-01905697-8

18. Nwachukwu BU, Patel BH, LuY, Allen AA, Williams RJ 3rd (2019) Anterior cruciate ligament repair outcomes: an updated systematic review of recent literature. Arthroscopy 35:2233-2247

19. Kandhari V, Vieira TD, Ouanezar H, Praz C, Rosenstiel N, Pioger C, Franck F, Saithna A, Sonnery-Cottet B (2020) Clinical outcomes of arthroscopic primary anterior cruciate ligament repair: a systematic review from the scientific anterior cruciate ligament network international study group. Arthroscopy 36:594-612

20. Papalia R, Torre G, Papalia G, Campi S, Maffulli N, Denaro V (2019) Arthroscopic primary repair of the anterior cruciate ligament in adults: a systematic review. Br Med Bull 131:29-42

\section{Publisher's Note}

Springer Nature remains neutral with regard to jurisdictional claims in published maps and institutional affiliations. 